\title{
Characterization and structural determination of 3A-amino-3A-deoxy-(2AS, 3AS)-cyclodextrins by NMR spectroscopy
}

\author{
Keiko Takahashi, Keita Andou and Shoji Fujiwara \\ The proton and carbon nuclear magnetic resonance (NMR) resonances have been assigned for 3A-amino-3A-deoxy-(2AS,3AS)- $\alpha-$, \\ $\beta$ - and $\gamma$-cyclodextrins (CyDs) $(3 \alpha, 3 \beta$ and $3 \gamma$ ). In these CyDs, a glucose residue has been replaced by an altro-pyranose \\ unit with an axial hydroxyl group. Assignments were made with one-dimensional NMR and COSY, TOCSY, ROESY and CHSHF \\ (heteronuclear shift correlation) spectra. Titration by NMR shift changes gave amino-group $\mathrm{pK}_{\mathrm{a}}$ values of 7.73 and 8.84 for $3 \beta$ \\ and 6A-amino-6A-deoxy- $\beta$-CyD (6ß), respectively.
}

Polymer Journal (2012) 44, 850-854; doi:10.1038/pj.2012.122; published online 20 June 2012

Keywords: altro-cyclodextrin; hydrogen bonding; NMR; structural assignment; titration

\section{INTRODUCTION}

Carbohydrates are key recognition elements in biological processes. However, in most cases, the role of carbohydrates and the detailed mechanisms of these events are still poorly understood. It seems that a clear model of the structure of carbohydrates is very important for understanding the role of carbohydrates in these processes. Carbohydrates look much simpler than other biomolecules as they differ from each other mainly by stereochemistry. However, carbohydrates actually have much more information capacity than proteins because they vary by linkages and stereochemistry and can be branched. The structure determination of complex oligosaccharides involves discovering the primary structure, stereochemistry, sequence, linkages and anomeric configurations; thus, it is actually a very challenging problem.

Cyclodextrins (CyDs) are naturally occurring cyclic carbohydrates consisting of 6-8 glucopyranosyl residues linked by $\alpha-1,4$ glycosidic bonds. They have a hydrophobic cavity and form inclusion complexes with various guest molecules in aqueous solution and solid state. ${ }^{1}$ CyDs have a major role in the development of supramolecular chemistry. Structural characterization is of particular significance for supramolecular host-guest complexes, which form the basis of most CyD applications in medicine, catalysis, food chemistry, separation and sensor technology. The early stages in CyD chemistry presented many chemists with a very impressive concept, that of a host-guest complex, which has been described as a ball in a bottomless pail. The main driving force is hydrophobic interaction. Other interactions, indeed hydrogen bonding between the guest and secondary hydroxyl groups, have sufficiently significant roles in that they recognize the ball. The so-called 'rims' of the pail also have to be considered. The rims have great potential to interact with the guest molecules through hydrogen-bond polar interaction supported by the hydrophobic cavity. ${ }^{2}$ Secondary hydroxyl groups, present at the wide rim of the cavity, are located in a more hydrophilic region. Thus, they have a more important role in molecular recognition through intra or inter hydrogen bonding than primary hydroxyl groups, which reside on the narrow rim. All of the CyDs are less soluble in water than acyclic saccharide, especially water solubility of $\beta$-CyD is anomaly among the CyDs. ${ }^{3}$ The secondary hydroxyl groups form intramolecular hydrogen bonds in which the 3-OH group of one glucose unit interacts with the $2-\mathrm{OH}$ group of the neighboring glucose unit of $\mathrm{CyD}$. In the $\alpha$-CyD molecule, one glucose unit is distorted and only four out of six possible hydrogen bonding were formed. In $\gamma$-CyD, its glucose units are not in the same plane and its structure is more flexible; therefore, these CyD have higher solubility than $\beta$-CyD. ${ }^{4}$ The solubility, which is attributed to the intramolecular hydrogen bonding of the 'rim', is the one piece of information, suggesting that the CyDs may not universally behave as monotonically graded series. ${ }^{3}$ Nuclear magnetic resonance (NMR) spectroscopy is the most common analytical technique used to gain information about carbohydrate molecules, their conformations and their overall structures. ${ }^{5}$ For the investigation on CyD complexes, NMR spectroscopy has also become an important tool. ${ }^{6}$ Other spectroscopic techniques, like UV-Vis absorption, fluorescence emission, circular dichroism and so on, are also suitable for thermodynamic study of the CyD-guest molecule interactions, however, they give only indirect information on the molecular structure of the inclusion complexes. When the guest molecule is included into the $\mathrm{CyD}$ cavity, the $\mathrm{H} 3$ and $\mathrm{H} 5$ protons of the $\mathrm{CyD}$ are by far most affected 
by the intermolecular interactions with the guest protons. This is the based on the expectation that inclusion complex formation of the guest with $\mathrm{CyD}$ will alter the chemical shift of $\mathrm{CyD}$ 's $\mathrm{H} 3$ and $\mathrm{H} 5$ protons, because they are oriented towards the CyD cavity. ${ }^{6,7}$ A typical structural inference is that if only $\mathrm{H} 3$ undergoes a shift in the presence of guest molecule, then the cavity penetration is shallow, whereas if $\mathrm{H} 5$ also shifts, the penetration is deep. Nuclear Overhauser Effect (NOE) information between $\mathrm{H} 3$ or $\mathrm{H} 5$ and the protons on the guest molecule give more direct information. Native $\mathrm{CyDs}$ are rigid molecules that offer limited utility in terms of size, shape and availability of chemically useful functional groups. This is because the $\alpha$-1,4-linked D-glucopyranosyl rings exclusively adopt the energetically favored $4 \mathrm{Cl}$ chair form that allows only limited rotation about the glycosidic bond. In order to add flexibility, we prepared several CyDs containing a hydrophobic substituent on a primary hydroxyl site, C6 site. $^{8-13}$ A phenyl group in these modified CyDs, known as the 'self-guest group' helps to control the cavity size. The modified CyDs also contain a flexible arm composed of $s p^{3}$ carbons between the CyD cavity and phenyl group. The structure causes guest-induced hydrophobic wall movement that forms an intramolecular complex. Monosubstituted CyDs lack the symmetry of free CyDs and have a distorted cavity with ring-current effect from the aromatic group of 'self-guest group' that create a magnetically inhomogeneous environment ${ }^{8}$ The distorted environment is clear from NMR studies of these CyD derivatives. ${ }^{8,10-13}$ Many guest-modified CyDs with additions to the primary hydroxyl site have been reported; however, very few studies that modify secondary hydroxyl site have been reported. We have studied 3A-amino-3A-deoxy(2AS,3AS)-CyD, a CyD in which the amino-substituted glucose residue was replaced by an altro-pyranose unit with axial hydroxyl groups as the starting material. ${ }^{14}$ The investigation of mono(2AS,3AS)- $\beta$-CyD (monoaltro- $\beta$-CyD) and its inclusion complex by NMR spectroscopy revealed that its hydrogen-bonding network makes it an adaptable host that could serve as an induced-fit enzyme model. ${ }^{15,16}$ In order to understand the inclusion behavior of secondary hydroxyl-group-substituted CyDs, the structural information and correct assignment of ${ }^{1} \mathrm{H}$ and ${ }^{13} \mathrm{C}$ resonances, especially, $\mathrm{H} 3, \mathrm{H} 5, \mathrm{C} 3$ and $\mathrm{C} 5$ for each glucose unit of $\mathrm{CyD}$ without guest molecule, are necessary. In this work, we investigated the structure and properties of 3A-amino-3A-deoxy-(2AS,3AS)-CyDs with NMR spectroscopy as the information to study modified CyDguest molecule complex. The complete assignment of the protons and carbons of 3A-amino-3A-deoxy-(2AS,3AS)- $\alpha$-, $\beta$ - and $\gamma$-CyDs $(3 \alpha, 3 \beta$ and $3 \gamma$, Figure 1), along with their characterization and structural determination, is reported.

\section{MATERIALS AND METHODS}

CyDs were purchased from Nihon Shokuhin Kako Co., Ltd. (Tokyo, Japan). Modified CyDs $3 \alpha, 3 \beta$ and $3 \gamma$ were purchased from Tokyo Chemical Industry Co. (Tokyo, Japan). $6 \mathrm{~A}$-amino-6A-deoxy- $\beta$-CyD ( $6 \beta$ ) was prepared according to the method reported previously. ${ }^{17,18}{ }^{1} \mathrm{H}$ NMR and ${ }^{13} \mathrm{C}$ NMR spectra were taken with a JEOL NM Lambda 500 spectrometer using a 5-mm AT probe $\left({ }^{1} \mathrm{H}\right.$ at $500 \mathrm{MHz}$ and ${ }^{13} \mathrm{C}$ at $125 \mathrm{MHz}$ : JEOL Ltd., Akishima, Japan). NMR spectra were obtained in $\mathrm{D}_{2} \mathrm{O}$ (Aldrich, Tokyo, Japan; $99.9 \% \mathrm{D}$ ) at $30^{\circ} \mathrm{C}$. Measurements were at a concentration of $17 \mathrm{~mm}$ for each $\mathrm{CyD}$. The $\mathrm{pH}$ of the solution was adjusted by adding hydrochloric acid $\mathrm{D}_{1}$ or sodium hydroxide $\mathrm{D}_{1}$ solutions in $\mathrm{D}_{2} \mathrm{O}$. Chemical shifts were reported in p.p m. and were referenced to acetone (2.100 p.p.m.).

\section{RESULTS AND DISCUSSION}

Assignments of ${ }^{1} \mathrm{H}$ and ${ }^{13} \mathrm{C}$ resonance of $3 \mathrm{~A}$-amino-3A-deoxy(2AS,3AS)-CyDs

The ${ }^{1} \mathrm{H}$ and ${ }^{13} \mathrm{C}$ NMR spectra of $3 \beta$ and $6 \beta$ were measured.(Supplementary Figure S1). Both monoamino-substituted CyDs contain one
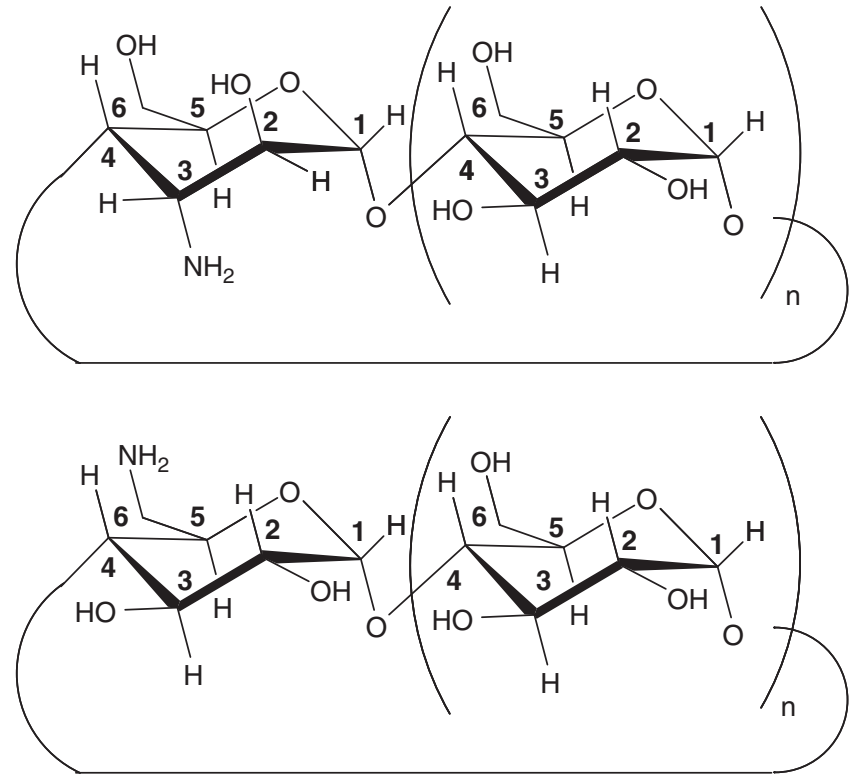

Figure 1 Structures of 3A-amino-3A-deoxy-(2AS,3AS)- $\alpha$-, $\beta$ - and $\gamma$-CyDs $(3 \alpha$; $n=5,3 \beta: n=6$ and $3 \gamma: n=7)$ and 6A-amino-6A-deoxy- $\alpha-, \beta-$ and $\gamma$-CyD $(6 \alpha: n=5,6 \beta: n=6$ and $6 \gamma: n=7)$.

modified glucose or altrose and unmodified glucopyranose rings. Compound $6 \beta$ has two spin systems, one from the modified residue and the other from unmodified residues. ${ }^{8}$ In detail, each protons on A ring were observed at 5.11, 3.67, 3.97, 3.50, 3.97, 3.01 and 3.25 p.p.m. for $\mathrm{A} 1, \mathrm{~A} 2, \mathrm{~A} 3, \mathrm{~A} 4, \mathrm{~A} 5, \mathrm{~A} 6$ and $\mathrm{A} 6^{\prime}$, respectively. A1, A4 and two A6 proton assignments have been reported previously. ${ }^{7} \mathrm{~A} 2, \mathrm{~A} 3$ and $\mathrm{A} 5$ resonances were determined with $\mathrm{H}-\mathrm{H}$ COrrelated SpectroscopY (COSY) spectra. In contrast, $\mathrm{CyD} 3 \beta$ has seven distinct spin systems, one for each residue. The belt of hydrogen bonds between the $3-\mathrm{OH}$ group of one glucose unit and the 2-OH group of the neighboring glucose unit rigidifies the structure. ${ }^{3}$ The primary $6-\mathrm{OH}$ does not take part in the hydrogen bonding, so it can rotate to partially block the hydrophobic cavity. This difference is reflected in the NMR spectra of $3 \beta$ and $6 \beta$.

The representative detailed procedures for assigning the ${ }^{1} \mathrm{H}$ and ${ }^{13} \mathrm{C}$ resonances are given below. Like free sugars, the anomeric protons exhibited characteristic downfield signals around 4.8 p.p.m. that are easy to distinguish, so the assignment began there. The anomeric protons of $3 \alpha$ exhibited six different resonances and are labeled A through $\mathrm{F}$ to represent the ring they were connected to. The widest doublet was observed at 4.7 p.p.m., close to the anomeric proton shift value of altrose. Assigning this signal to the altrose A ring made it possible to assign all the resonances on the A ring, which contained the amine. By using COSY, one could walk around the ring to assign the H2-H6 signals. Unfortunately, the signals overlapped so severely that some assignments may be ambiguous (Supplementary Figure S2).

The TOtally Correlated SpectroscopY (TOCSY) spectra allowed us to group each anomeric proton with the cross-peaks representing the other protons on its individual sugar unit. Because the C4 and C6 signals were easy to discriminate from the other resonances $(\mathrm{C} 2, \mathrm{C} 3$ and $\mathrm{C} 5$ ) in the ${ }^{13} \mathrm{C}$ NMR spectra, the assignment of the $\mathrm{H} 4$ and $\mathrm{H} 6$ proton resonances by heteronuclear shift correlation (CHSHF) was straightforward.

In each $\mathrm{CyD}$, the distance between the $\mathrm{H} 1$ of one glucopyranose unit and the $\mathrm{H} 4$ of its neighboring unit across the $\alpha-1,4$ glycosidic bond was 
close enough to give rise to through-space NOE enhancements, which allowed the groups of signals to be assigned to their corresponding rings (A-F). When one $\mathrm{H} 4$ resonance had a negative cross-peak with an $\mathrm{H} 1$ resonance of an A unit, all the signals in the latter system could be assigned to the $\mathrm{B}$ unit. In a similar manner, all the signals were attributed to their respective glucopyranose units. The validity of the sequential assignments was confirmed, as the $\mathrm{H} 1$ resonance of the $\mathrm{F}$ unit had an NOE cross-peak with the $\mathrm{H} 4$ resonance of the A unit. Therefore, by using CHSHF, TOCSY and Rotating frame nuclear. Overhauser Effect SpectroscopY (ROESY) methods, all resonances could be assigned (Supplementary Figures S3-S5).

To confirm the assignments, we reinvestigated to make sure that the assignments accounted for all peaks in the one-dimensional spectrum and all cross-peaks in the two-dimensional spectra. We also checked to see whether the peaks had reasonable intensities and the coupling constants were consistent. With complete proton assignments, all carbons could be easily assigned. The chemical shifts assigned to the 3 -aminoaltrose residue were the same as those reported previously. ${ }^{19}$ In the same manner as $3 \alpha$, the assignments of the protons and carbons of $3 \beta$ and $3 \gamma$ were accomplished. In Figures 2 and 3 , the ${ }^{1} \mathrm{H}$ and ${ }^{13} \mathrm{C}$ NMR spectra of $3 \alpha, 3 \beta$ and $3 \gamma$ are presented with assignments.

\section{$\mathrm{NH}_{2}-\mathrm{NH}_{3}{ }^{+}$equilibrium}

One of the fundamental characteristics of amino CyDs is their ionization constants $\left(\mathrm{pK}_{\mathrm{a}} \mathrm{s}\right)$. NMR shift titrations are one of the most common methods to determine association constants of $\mathrm{CyDs}{ }^{6}$ however, the acid-base equivalence point of a titration is often carried out using with a color indicator or $\mathrm{pH}$ meter. The indicator changes color at the end point of the titration. This is a common and easy method, but it requires a lot of sample. NMR titration is an efficient way to exactly determine a $\mathrm{pK}_{\mathrm{a}}$ on the microscale.

Figure 4 shows the ${ }^{1} \mathrm{H}$ NMR spectra of $3 \beta$ in solutions of various $\mathrm{pH}$. Under acidic conditions, the $\mathrm{H} 3$ signal of the altrose residue (A3) was observed at 3.70 p.p.m. Under basic conditions, the signal was observed at 2.70 p.p.m. The dependence of this chemical shift on $\mathrm{pH}$ is shown in Supplementary Figure S6. The protons on the secondary hydroxyl site (A2 and A3), which is wider rim of CyD cavity, shifted upfield with increasing $\mathrm{pH}$, hence that at the primary hydroxyl site (A5 and A6), which is the narrow rim of $\mathrm{CyD}$, did not change. The pKa of secondary hydroxyl groups has been reported to be $12.08-12.33 .^{20,21}$ An upfieldshift was also observed at $\mathrm{pH}$ values $>12$, probably due to the dissociation of secondary hydroxyl groups. The $\mathrm{pH}$ at the end point of titration was about 10. From the titration curve of the A3 shifts, the $\mathrm{pK}_{\mathrm{a}}$ was calculated to be 7.73. In the same manner (Supplementary Figure S7), the $\mathrm{pK}_{\mathrm{a}}$ of $6 \beta$ was calculated to be 8.84. Normally, the $\mathrm{pK}_{\mathrm{a}} \mathrm{s}$ of amino groups are well $>8 .{ }^{17}$ The lower values for these amino groups located on the rim of the CyD cavity on $3 \beta$ should be attributable to the effect of the many proximal hydroxyl groups and/or the hydrophobic cavity itself.

\section{Structures of the macrocyclic rings}

Native CyDs exhibit only a single set of NMR resonances as if there were only one glucopyranose unit because of their symmetry.

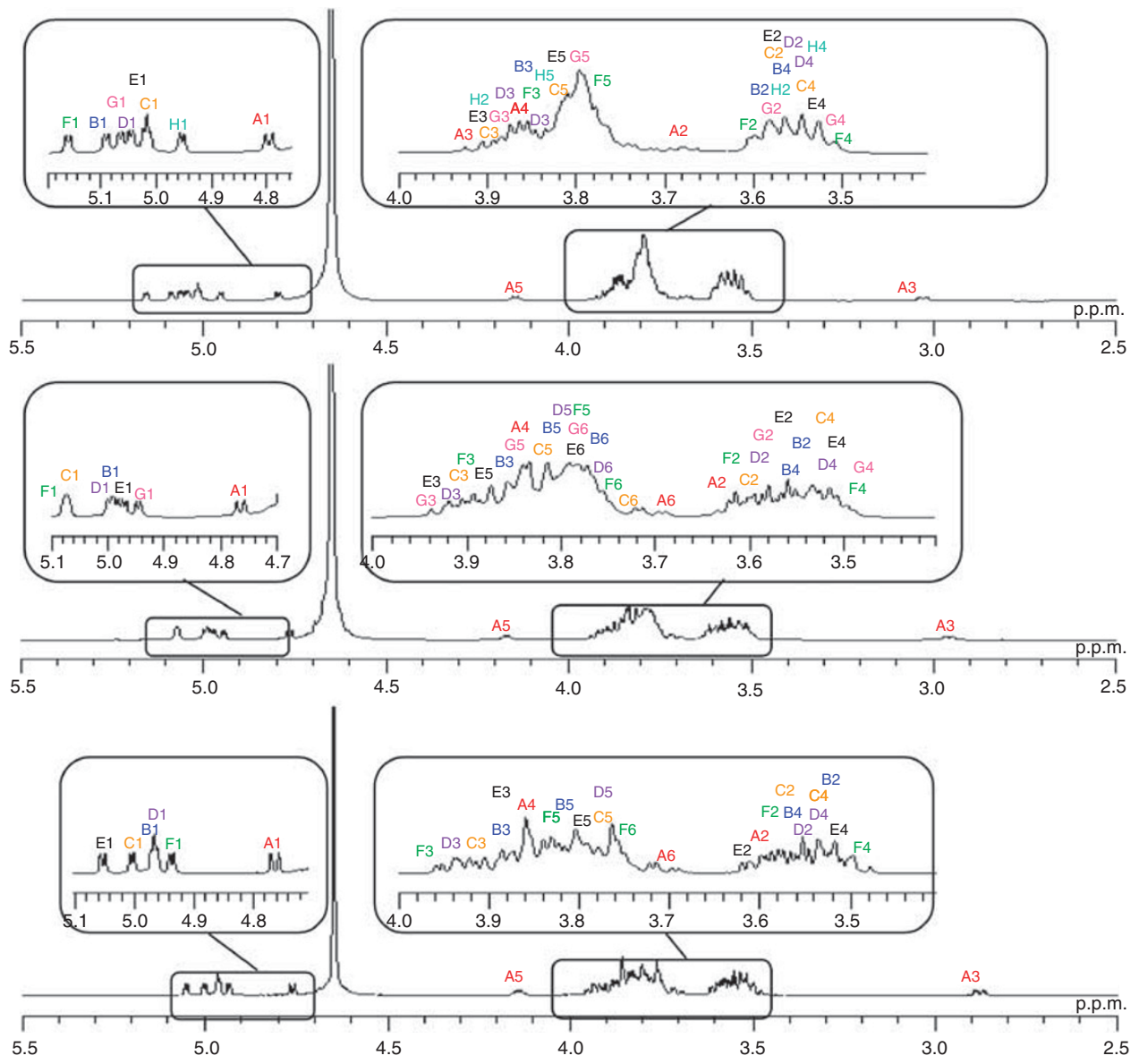

Figure 2 The $500-\mathrm{MHz}^{1} \mathrm{H}$ NMR spectra of $3 \alpha$ (bottom; $\mathrm{pH}$ : 9.17), $3 \beta$ (middle; $\mathrm{pH}$ : 9.20) and $3 \gamma$ (top; $\mathrm{pH}: 8.88$ ) in $\mathrm{D}_{2} \mathrm{O}$ at $30^{\circ} \mathrm{C}$. 


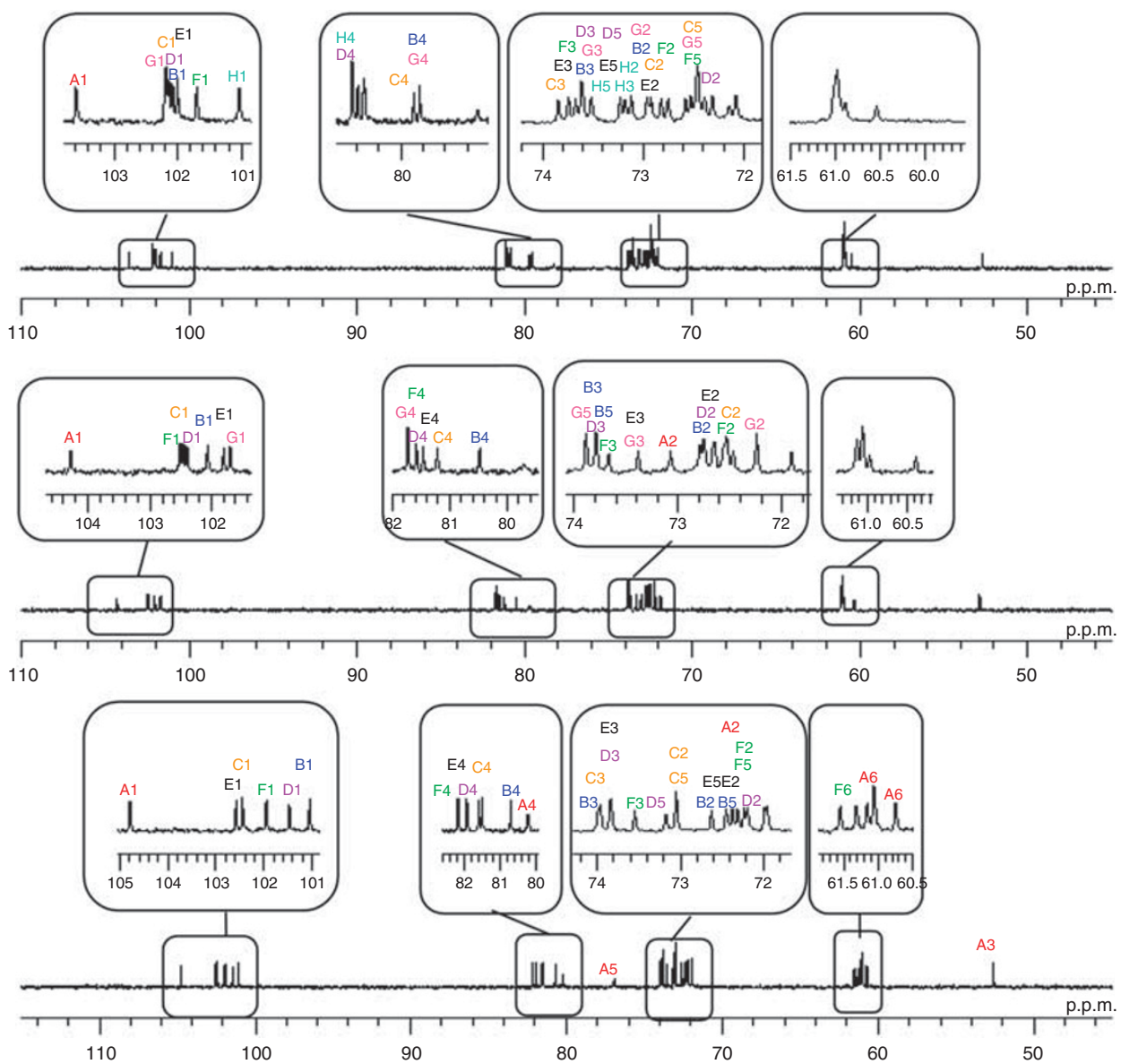

Figure 3 The $125-\mathrm{MHz}{ }^{13} \mathrm{C}$ NMR spectra of $3 \alpha$ (bottom; $\mathrm{pH}: 9.17$ ), $3 \beta$ (middle; $\mathrm{pH}: 9.20$ ) and $3 \gamma$ (top; $\mathrm{pH}: 8.88$ ) in $\mathrm{D}_{2} \mathrm{O}$ at $30^{\circ} \mathrm{C}$.

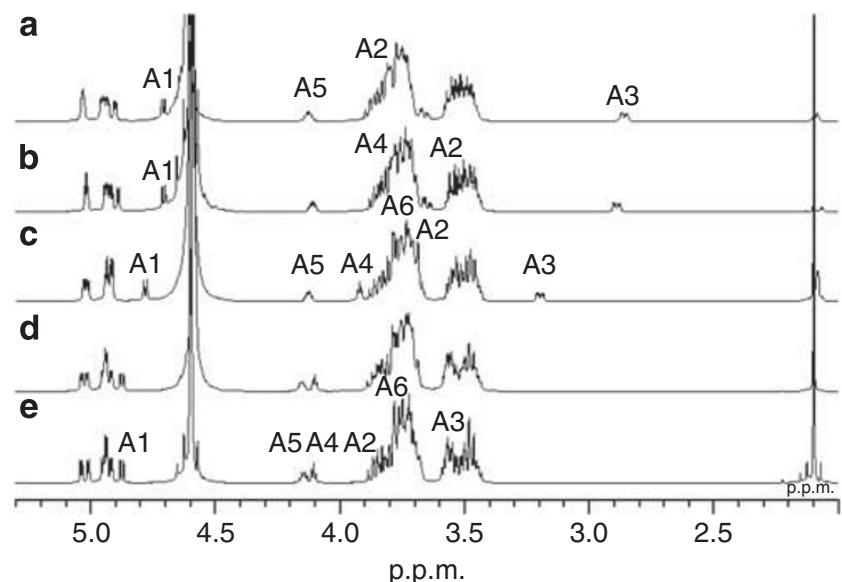

Figure 4 The ${ }^{1} \mathrm{H}$ NMR spectra of $3 \beta$ in $\mathrm{D}_{2} \mathrm{O}$ at $30{ }^{\circ} \mathrm{C}, \mathrm{pH}: 11.24$ (a), 9.72 (b), 8.02 (c), 5.99 (d) and 2.26(e). The proton resonances assigned to altorose ring (A ring) are marked.

However, for $3 \alpha, 3 \beta$ and $3 \gamma$, due to the $3 \mathrm{~A}$-amino-altrose residue, the $\mathrm{C}_{6}, \mathrm{C}_{7}$ and $\mathrm{C}_{8}$ symmetries of the macrocyclic rings were broken. In the spectra of $3 \mathrm{~A}$-aminoaltoro-CyDs, sets of NMR resonances representing each pyranoglycoside were relatively well discriminated.
This is evident in the $\mathrm{H} 1$ and $\mathrm{C} 1$ resonances (Supplementary Figure S2). The chemical shifts of the $\mathrm{H} 1$ and $\mathrm{H} 4$ protons and $\mathrm{C} 1$ and $\mathrm{C} 4$ carbons are known to reflect the conformation around the glycosidic bonds. ${ }^{20-22}$ A change in the observed ${ }^{13} \mathrm{C}$ chemical shift of ca. 2 p.p.m. corresponds to an average change in the torsion angle $(\psi)$ of $c a$. $10^{\circ} .22$ The lowest chemical shift of $\mathrm{C} 1$ was assigned as the substituted altrose unit of the macrocyclic ring. The $\Delta \delta$ values of $3 \alpha, 3 \beta$ and $3 \gamma$ were $4.74,2.49$ and 2.56 , respectively (Table 1 ), which means that the difference between the narrowest and widest $\psi$ was about $13-24^{\circ}$. Whether the amino group was in its basic or protonated form, the ${ }^{13} \mathrm{C}$ spectra presented well-discriminated signals. We have reported that self-guest-modified CyDs had complex NMR spectra due to the ring-current effects of the phenyl group. The flexibility and distortion of those CyDs' macrocyclic ring were due to phenyl group. The CyDs studied here had no aromatic groups and only an amino group on the altrose residue. The large $\mathrm{H}$ and $\mathrm{C}$ resonance displacements may be ascribed to conformational changes, resulting from the hydrogen bonding between hydroxyl groups on each rim of the cavity. ${ }^{13} \mathrm{C}$ chemical shifts on $3 \alpha, 3 \beta$ and $3 \gamma$ were observed divisionally. When these CyDs include other molecule as guest, the resonance of the proton, which is both inside or outside cavity, would be shifted and the NOE with them suggests the structure of CyD-guest molecule. The division of the resonances should be a good advantage for the measurement. 
Table 1 The ${ }^{13} \mathrm{C}$ Chemical shifts of the anomeric (C1) and (C4) carbons

\begin{tabular}{|c|c|c|c|c|c|}
\hline \multirow{2}{*}{$\delta$ per p.p.m. } & \multicolumn{5}{|c|}{ Compound } \\
\hline & $\beta$ & $6 \beta$ & $\begin{array}{c}3 \alpha \\
(p H: 9.17)\end{array}$ & $\begin{array}{c}3 \beta \\
(p H: 9.20)\end{array}$ & $\begin{array}{c}3 \gamma \\
(p H: 8.88)\end{array}$ \\
\hline $\mathrm{C} 1$ & 103.71 & $\begin{array}{l}103.06(A) \\
102.87\end{array}$ & $\begin{array}{l}104.79(\mathrm{~A}) \\
101.05(\mathrm{~B}) \\
102.44(\mathrm{C}) \\
101.48(\mathrm{D}) \\
102.57(\mathrm{E}) \\
101.95(\mathrm{~F})\end{array}$ & $\begin{array}{l}104.29(\mathrm{~A}) \\
102.51(\mathrm{~B}) \\
102.46(\mathrm{C}) \\
101.40(\mathrm{D}) \\
102.07(\mathrm{E}) \\
101.80(\mathrm{~F}) \\
101.70(\mathrm{G})\end{array}$ & $\begin{array}{l}103.60(\mathrm{~A}) \\
102.01(\mathrm{~B}) \\
102.09(\mathrm{C}) \\
102.15(\mathrm{D}) \\
102.09(\mathrm{E}) \\
101.71(\mathrm{~F}) \\
102.20(\mathrm{G}) \\
101.04(\mathrm{H})\end{array}$ \\
\hline $\begin{array}{l}\Delta \delta \text { per p.p.m. } \\
\mathrm{C} 4\end{array}$ & $-\overline{82.74}$ & $\begin{array}{l}0.19 \\
84.00(A) \\
82.04\end{array}$ & $\begin{array}{r}3.74(1.52) \\
80.25(\mathrm{~A}) \\
80.74(\mathrm{~B}) \\
81.61(\mathrm{C}) \\
81.53(\mathrm{D}) \\
81.96(\mathrm{E}) \\
82.20(\mathrm{~F})\end{array}$ & $\begin{array}{c}2.89(1.11) \\
-(A) \\
80.49(B) \\
80.49(C) \\
81.47(D) \\
81.22(E) \\
81.55(F) \\
81.73(G)\end{array}$ & $\begin{array}{c}2.56(1.11) \\
-(\mathrm{A}) \\
79.53(\mathrm{~B}) \\
-(\mathrm{C}) \\
81.12(\mathrm{D}) \\
-(\mathrm{E}) \\
(\mathrm{F}) \\
(\mathrm{G}) \\
81.12(\mathrm{H})\end{array}$ \\
\hline$\Delta \delta$ per p.p.m. & - & 1.96 & 1.95 & 1.24 & 1.59 \\
\hline
\end{tabular}

\section{CONCLUSIONS}

The proton and carbon NMR resonances of CyD derivatives $3 \alpha, 3 \beta$ and $3 \gamma$ have been completely and thoroughly assigned. A titration curve generated from signals in NMR spectra at different $\mathrm{pH}$ values gave the $\mathrm{pK}_{\mathrm{a}}$ values of the substituted amino groups of $3 \beta$ and $6 \beta$ as 7.73 and 8.84, respectively. Chemical shifts can substitute for colorimetric reagents to allow microscale titrations. 3A-Amino-3Adeoxy-(2AS,3AS)-CyDs have a distorted macrocyclic ring, even under acidic conditions. This phenomenon has been attributed to hydrogen bonding between hydroxyl groups of the CyDs.

\section{ACKNOWLEDGEMENTS}

We thank Dr Toshiaki Narusawa for his useful suggestions for studying the molecular structures and Mr Takuma Naganuma for assisting with the experiments.
1 Myron, L., Bender, M. L. \& Komiyama, M. Cyclodextrin Chemistry (Springer-Verlag, New York, 1978).

2 Takahashi, K. Reaction mediated by cyclodextrins. in Molecular Encupsulation Organic Reactions in Constrained Systems (ed. Brinker, U. H. \& Mieusset, J.-L.) 91-116 (WILEY, West Sussex, UK, 2010).

3 Connors, K. A. The stability of cyclodextrin complexes in solution. Chem. Rev. 97, 1325-1357 (1997)

4 Uekama, K., Hirayama, F. \& Irie, T. Cyclodextrin drug carrier systems. Chem. Rev. 98 2045-2076 (1998).

5 Duus, J. Ø., Gotfredsen, C. H. \& Bock, K. Carbohydrate structural determination by NMR spectroscopy: modern methods and limitations. Chem. Rev. 100, 4589-4614 (2000).

6 Schneider, H.-J., Hacker, F., Rüdiger, V. \& Ikeda, H. NMR studies of cyclodextrins and cyclodextrin complexes. Chem. Rev. 98, 1755-1785 (1998).

7 Yamamoto, Y. \& Inoue, Y. NMR studies of cyclodextrin inclusion complex. J. Carbohydr. Chem. 8, 29-46 (1998)

8 Saka, W., Yamamoto, Y., Inoue, Y., Chujo, R., Takahashi, K. \& Hattori, K. ${ }^{1}$ HNMR study of conformational of formyl---phenylalanyl-6-deoxy-6-amino- cyclomalsoheptaose that has excellent ability of chiral recognition. Bull. Chem. Soc. Jpn. 63, 3175-3182 (1990).

9 Takahashi, K. Fluorescence of 1-naphthol induced by 2:1 complexation with $6 N(N$ ' formyl--L-phenylalanyl)-deoxyamino- $\beta$-cyclodextrin. J. Chem. Soc. Chem. Comm. 929-930 (1991)

10 Takahashi, K. Preparation and molecular recognition ability of mono[6-deoxy-6-(Ltyrosylamino)]- $\beta$-cyclodextrin. Formation and guest binding properties of distorted cavity formed outside the parent cyclodextrin. Bull. Chem. Soc. Jpn 66, 550-554 (1993).

11 Takahashi, K., Imotani, K. \& Kitsuta, M. Formation of superstructure composed of modified cyclodextrins as molecular 'blocks' in aqueous solution with host-guest complexation; correlation of chemical structure of modified group with complexation. Polymer J. 33, 242-247 (2001)

12 Takahashi, K. \& Furushoh, R. Diastereomeric differences of 'Pendant Type' monosubstituted cyclodextrins, mono-[6-deoxy-6N(N-formyl L- and D-phenylglycylamino)]- $\beta$-cyclodextrin in conformation and 'Induced-fit' behavior. Polymer J. 28, 458-464 (1996).

13 Suzuki, I., Kato, Y., Egawa, Y., Anzai, J., Wadamori, M., Yokomizo, H. \& Takahashi, K. Structural aspects of marked difference in intramolecular exciplex emissions from selfcomplexes of $\beta$-cyclodextrin modified with (R) or (S)-1-(1-aminoethyl)naphthalene. J. Mol. Struct. 602-603, 223-231 (2002).

14 Fujiwara, S. \& Takahashi, K. Molecular properties of mono guest-modified cyclodextrins on the secondary site. Supramol. Chem. 23, 156-159 (2011).

15 Fujita, K., Chen, W.-H., Yuan, D.-Q., Nogami, T., Koga, T., Fujioka, T., Mihashi, K. Immuel, S. \& Lichtenthaler, F. W. Guest-induced conformational change in a flexible

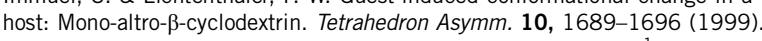

16 Hakkarainen, B., Fujita, K., Immel, S., Kenne, L. \& Sandström, C. ${ }^{1}$ H NMR studies on the hydrogen-bonding network in mono-altro- $\beta$-cyclodextrin and its complex with adamantane-1-carboxylic acid. Carbohydr. Res. 340, 1539-1545 (2005).

17 Petter, R. C., Salek, J. S., Sikorski, T., Kumaravel, G. \& Lin, F.-T. Cooerative binding by aggregated mono-6-(alkylamino)-B-cyclodextrins. J. Am. Chem. Soc. 112, 3860-3868 (1990)

18 Hamasaki, K., Ikeda, H., Nakamura, A., Ueno, A., Toda, F., Suzuki, I. \& Osa, T. Fluorescence sensors of molecular recognition. modified cyclodextrins capable of exhibiting gust-responsive twisted intramolecular charge transfer fluorescence. J. Am. Chem. Soc. 115, 5035-5040 (1993)

19 Ikeda, H., Nagano, Y., Du, Y., Ikeda, T. \& Toda, F. Modifications of the secondary hydroxyl side of $\alpha$-Cyclodextrin and NMR studies of them. Tetrahedron Lett. 31, 50455048 (1990)

20 Gelb, R. I., Schwartz, L. M., Bradshaw, J. J. \& Laufer, D. A. Acid dissociation of cyclohexaamylose and cycloheptaamylose. Bioorg. Chem. 9, 299-304 (1980).

21 Gelb, R. I. Schwartz, L. M. \& Laufer, D. A. Acid dissociation of cyclooctaamylose. Bioorg. Chem. 11, 274-280 (1982).

22 Bock, K., Brigbole, A. \& Sigurskjold, B. W. Conformational dependence of ${ }^{13} \mathrm{C}$ nuclear magnetic resonance chemical shifts in oligosaccharides. J. Chem. Soc. Perkin Trans. 2 , 1711-1713 (1986).

Supplementary Information accompanies the paper on Polymer Journal website (http://www.nature.com/pj) 